\title{
Efficacy of Taurine in Altering Somatostatin and GAD Levels in a Pancreatic $\beta$ cell Line
}

\author{
C. M. Cuttitta, ${ }^{*}$ S. R. Guariglia, ${ }^{* *}$ A. El Idrissi, $* * *$ and W. J. L'Amoreaux**** \\ * Department of Biology, College of Staten Island, Staten Island, NY 10314 \\ ** Advanced Imaging Facility and Department of Biology, College of Staten Island, Staten Island, \\ NY 10314 \\ *** Center for Developmental Neuroscience, and Department of Biology, College of Staten Island, \\ Staten Island, NY 10314
}

**** Advanced Imaging Facility, Center for Developmental Neuroscience, and Department of Biology, College of Staten Island, Staten Island, NY 10314

Release of insulin and glucagon from the endocrine pancreas is regulated by a number of neurotransmitters, including glutamate, GABA, and somatostatin. In the GABAergic system, GABA binding to $\mathrm{GABA}_{\mathrm{A}}$ receptors opens chloride channels on $\alpha$ cells, hyperpolarizing these cells thereby regulating glucagon release. We have shown that the taurine is a potent GABA agonist in the brain, hyperpolarizing post-synaptic neurons [1,2]. We have also previously shown that taurine treatment alters glucose homeostasis and pancreas remodeling [3] and alters insulin and GABA levels in a pancreatic $\beta$ cell line (Hit-T15) [4]. In the intact pancreas, we believe that taurine interacts with the GABAergic system in the developing pancreas to decrease $\mathrm{GABA}_{\mathrm{A}}$ subunit expression that affects both GAD and GABA expression in $\beta$ cells, much like in neurons [5]. Here, we test the efficacy of taurine in altering somatostatin and GAD expression in Hit cells.

In pancreatic islets, glucose uptake serves as an electrogenic switch to regulate insulin and GABA release. With concentrations $>2.8 \mathrm{mM}$, glucose uptake and glycolytic processing increases cytoplasmic ATP concentrations, shutting off ATP-sensitive $\mathrm{K}^{+}$channels. In skeletal muscle, taurine can also inactivate these $\mathrm{K}_{\mathrm{ATP}}$ channels. Inhibition of the $\mathrm{K}_{\mathrm{ATP}}$ channels increase $\mathrm{Ca}^{2+}$ currents required for exocytosis. We tested whether taurine treatment can affect somatostatin release and whether taurine directly affects GAD expression in $\beta$ cells.

The $\beta$ cell line were grown in culture, treated with either $1 \mathrm{mM}$ glucose (a concentration that does not promote $\mathrm{Ca}^{2+}$-dependent exocytosis, $3 \mathrm{mM}$ glucose (a concentrations know to promote $\mathrm{Ca}^{2+}$ dependent exocytosis) and $1 \mathrm{mM}$ taurine, which also promote $\mathrm{Ca}^{2+}$-dependent exocytosis. Cells were treated for $24 \mathrm{hr}$, fixed and prepared for immunohistochemical analyses. The data were collected by confocal microscopy. Gain and offset for the acquisitions were identical for these three treatments. Statistical analyses were performed on intensity values using a one-way ANOVA and Dunn's post-test analyses.

Our data show that while $3 \mathrm{mM}$ glucose significantly decreases somatostatin and increases GAD levels (Figs. 1, 2) compared to controls, $1 \mathrm{mM}$ taurine is insufficient to elicit this response. Since taurine has been reported to affect release of insulin and GABA from large dense core vesicles, we demonstrate here that the mechanism by which taurine promotes exocytosis of these vesicles is different from the mechanism by which somatostatin is released. Further, we provide evidence that the taurine-dependent upregulation of GAD expression requires a feedback mechanism from $\alpha$ cells. 
References

[1] A. El Idrissi et al., J. Biomed. Sci. 17 (Suppl. 1) (2010) S15.

[2] W. J. L'Amoreaux et al., J. Biomed. Sci. 17 (Suppl. 1) (2010) S14.

[3] A. El Idrissi et al., Adv. Exp. Biol. Med. 643 (2008) 353.

[4] W. J. L'Amoreaux et al., J. Biomed. Sci. 17 (Suppl. 1) (2010) S11.

[5] A. El Idrissi et al., Neurosci. Lett. 377 (2005) 141.

TABLE 1. Statistical analyses of relative intensities values for somatostatin and GAD67 immunoreactivity. $\mathrm{P}$ values are reported comparing data to $1 \mathrm{mM}$ glucose, which serves as a control.

\begin{tabular}{|c|c|c|c|c|}
\hline & \multicolumn{2}{|c|}{ Somatostatin } & \multicolumn{2}{|c|}{ GAD67 } \\
\hline $1 \mathrm{mM}$ glucose & $\begin{array}{l}\text { Mean: } 41.0 \\
\text { SE: }+1.6\end{array}$ & & $\begin{array}{l}\text { Mean: } 17.2 \\
\text { SE: }+0.6\end{array}$ & \\
\hline $3 \mathrm{mM}$ glucose & $\begin{array}{l}\text { Mean: } 19.8 \\
\text { SE: }+0.6\end{array}$ & $\mathrm{p}<0.001$ & $\begin{array}{l}\text { Mean: } 22.3 \\
\text { SE: }+1.5\end{array}$ & $\mathrm{p}<0.05$ \\
\hline $1 \mathrm{mM}$ taurine & $\begin{array}{l}\text { Mean: } 43.0 \\
\text { SE: }+1.4\end{array}$ & $p>0.05$ & $\begin{array}{l}\text { Mean: } 16.1 \\
\text { SE: }+0.7\end{array}$ & $p>0.05$ \\
\hline
\end{tabular}

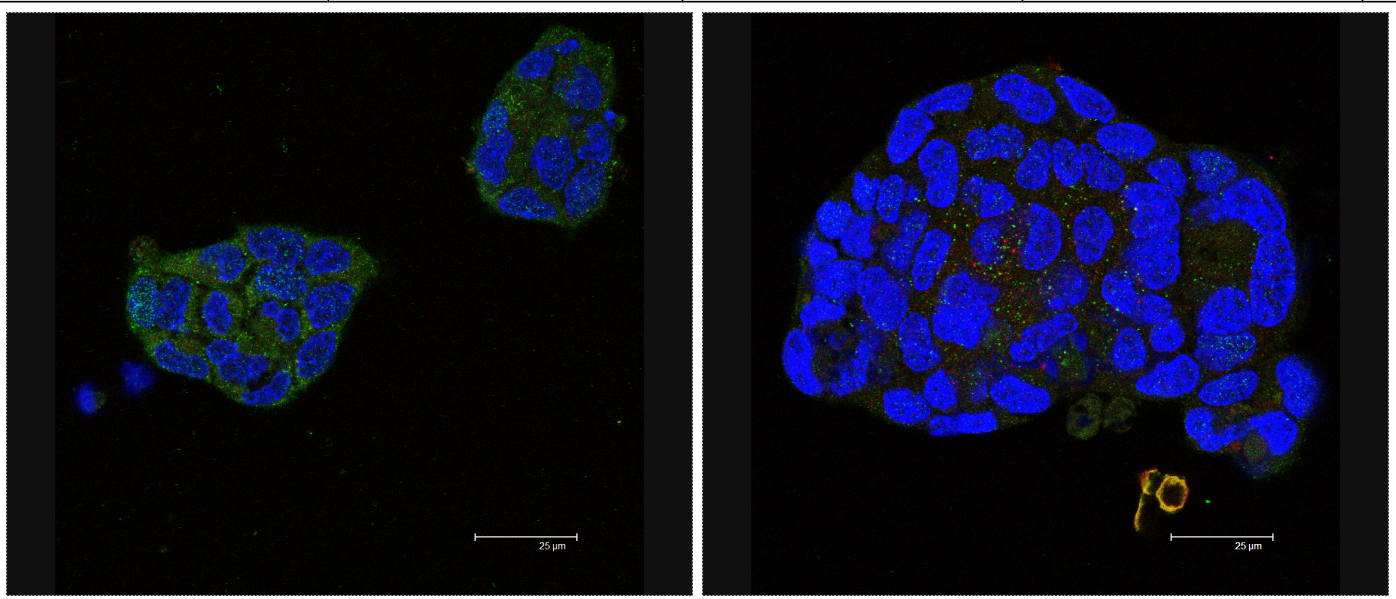

FIG. 1. Hit-T15 cells treated with $1 \mathrm{mM}$ glucose. Staining for somatostatin (green) and GAD67 (red). This treatment serves as a control for this cell line. Scale bar $=25 \mu \mathrm{m}$.

FIG. 2. Hit-T15 cells treated with $3 \mathrm{mM}$ glucose. Somatostatin levels are decreased and GAD67 increased with this treatment. Scale bar $=25 \mu \mathrm{m}$.

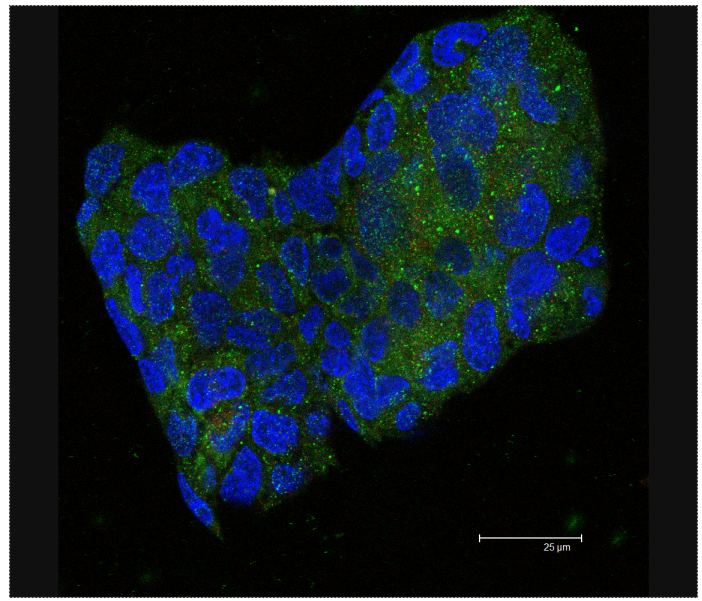

FIG. 3. Treatment with $1 \mathrm{mM}$ taurine has no effect on the release of somatostatin or expression of GAD67. Scale bar $=25 \mu \mathrm{m}$. 